\title{
Calcium enhances antiinflammatory activity of aspirin in albino rats
}

\author{
A.S. Karnad, P.A. Patil, S.I. Majagi
}

Department of Pharmacology and

Pharmacotherapeutics,

J.N. Medical College,

Nehru Nagar,

Belgaum-590 010. India

Received: 19.10.2005

Revised: 2.3.2006

Accepted: 24.4.2006

Correspondence to:

Suneel Ishwar Majagi

E-mail: suneelmajagi@yahoo.co.in

\begin{abstract}
Objective: To evaluate the effects of calcium carbonate and calcium gluconate on acute and subacute inflammation, and to study their possible interactions with aspirin, verapamil and magnesium sulphate.

Materials and Methods: Calcium carbonate in the dose of 10, 25, $50 \mathrm{mg} / \mathrm{kg}$, calcium gluconate in the dose of 5, 10, 25, $50 \mathrm{mg} / \mathrm{kg}$, and aspirin in the dose of 54, $200 \mathrm{mg} / \mathrm{kg}$ were administered orally in different groups of albino rats, to study their effect on inflammation induced by carrageenan or a foreign body. Aspirin $(54 \mathrm{mg} / \mathrm{kg}$ ) was administered either with calcium carbonate $(10 \mathrm{mg} / \mathrm{kg})$ or calcium gluconate $(5 \mathrm{mg} / \mathrm{kg})$ to separate groups in order to study their interaction, especially with reference to gastric ulceration. Similarly, possible interactions of verapamil ( $4 \mathrm{mg} / \mathrm{kg}$ ) with calcium carbonate $(10 \mathrm{mg} / \mathrm{kg}$ ) and magnesium sulfate $(500 \mathrm{mg} / \mathrm{kg})$ with calcium carbonate $(50 \mathrm{mg} / \mathrm{kg}$ ) were also studied.

Results: Both calcium carbonate and calcium gluconate produced significant antiinflammatory activity in acute as well as subacute inflammation models and was comparable to that of aspirin. Sub-antiinflammatory dose of calcium salts potentiated the antiinflammatory activity of aspirin. Verapamil also potentiated the anti-inflammatory activity of calcium carbonate while magnesium sulfate antagonized the antiinflammatory activity of calcium carbonate in both the models of inflammation.

Conclusion: Co-administration of calcium salt potentiated the antiinflammatory response and minimized the gastro-toxicity of aspirin.

KEY WORDS: Acetylsalicylic acid, antiinflammatory agent, calcium channel blocker, calcium salt, magnesium salt.
\end{abstract}

\section{Introduction}

Inflammation continues to be an area of great interest for research, probably due to the nonavailability of a safer and more effective antiinflammatory agent. In recent years increased understanding of the inflammatory mechanism and the mediators involved has led to the development of newer antiinflammatory agents like monoclonal antibodies and antagonists of inflammogens. Interestingly, several other drugs like minocycline, ${ }^{[1]}$ ascorbic acid ${ }^{[2]}$ and calcium salts (calcium dobesilate, calcium hydroxide, calcium pentosan polysulfate) ${ }^{[3-5]}$ have also been reported to possess antiinflammatory property. Earlier, calcium chloride was advocated for the treatment of urticaria, acute oedema, pruritus and erythema, ${ }^{[6]}$ calcium carbonate and calcium gluconate for the treatment of insect stings ${ }^{[7]}$ and calcium hydroxide to suppress periapical inflammation in dental practice. ${ }^{[8,9]}$ These reports indicate that calcium salts possess antiinflammatory property.
On the contrary, in another study ${ }^{[10]}$ locally applied calcium neither inhibited oedema formation nor reduced inflammatory signs. Similarly, calcium salts failed to prevent effusion across capillary endothelial membrane. ${ }^{[11]}$ Moreover, calcium gluconate has been reported to produce pancreatitis in cats. ${ }^{[12]}$ All these indicate that calcium salts are not only devoid of antiinflammatory activity but may be pro-inflammatory.

Calcium channel blockers have also been reported to possess antiinflammatory property ${ }^{[13]}$ and a calcium-channel antagonist, verapamil, has been shown to potentiate the antiinflammatory activity of aspirin. ${ }^{[14]}$ These studies probably support the pro-inflammatory activity of calcium salts.

In view of these controversies, the present study was planned to investigate the effect of calcium carbonate and calcium gluconate on acute and subacute inflammation in Wistar rats. The other objective was to investigate the interaction of calcium salts with aspirin, as well as with verapamil. 


\section{Materials and methods}

\section{Animals}

Male albino Wistar rats (150-270 g) were used. The animals were acclimatized to normal laboratory conditions with 12:12 h natural light:dark cycle and were fed with standard laboratory diet with free access to water.

\section{Acute inflammation}

Rats were divided into several groups of six each. They were starved overnight with water ad libitum prior to the day of experiment. The control group received $0.5 \mathrm{ml}$ of $1 \%$ gum acacia suspension orally, while the other groups received different drug treatments as detailed below.

Thirty minutes after drug administration, acute inflammation was induced by injecting $0.05 \mathrm{ml}$ of $1 \%$ carrageenan (Sigma co., St Louis) in normal saline into the subplantar region of the left hind paw, as per the method of Winter $e t$ al. ${ }^{[15]}$ A mark was applied on the leg at the malleolus to facilitate subsequent readings. The paw oedema volume was measured by mercury displacement with the help of a plethysmograph at $0,0.5,1,3$ and $5 \mathrm{~h}$ after injecting carrageenan. The difference between $0 \mathrm{~h}$ and subsequent readings was considered as oedema volume. The percentage inhibition of oedema in various groups was calculated using the formula:

$\%$ oedema inhibition $=1-\frac{\mathrm{Vt}}{\mathrm{Vc}} \quad \mathrm{X} \quad 100$

Vt and Vc were oedema volume in the drug-treated and control groups respectively.

\section{Subacute inflammation}

Subacute inflammation was induced by a slightly modified method of D'Arcy et al. ${ }^{[15]}$ Seven groups of six rats each were used. Under light ether anaesthesia, hair in the axilla and the groin were clipped, and two sterile cotton pellets, weighing $10 \mathrm{mg}$ each and two sterile grass piths $(25$ X $2 \mathrm{~mm})$ were implanted subcutaneously, through a small incision, either in the axilla or the groin, at random. The wounds were then sutured and the animals were caged individually after recovery from anaesthesia. Aseptic precautions were taken throughout the experiment. The rats then received treatments as shown below. The treatment was started on the day after the implantation and was repeated every $24 \mathrm{~h}$, regularly for 10 days.

On the 11th day the rats were sacrificed with an overdose of ether anaesthesia, and the cotton pellets, grass piths and the stomachs were removed. The pellets, freed from extraneous tissue, were dried overnight at $60^{\circ} \mathrm{C}$ and their dry weight measured. Net granuloma formation was calculated by subtracting the initial weights of cotton pellet from the final weights. Mean granuloma dry weight for the various groups was calculated and expressed as $\mathrm{mg} / 100 \mathrm{~g}$ body weight. The grass piths were preserved in $10 \%$ formalin for histopathological study after H\&E staining.

\section{Ulcer index}

The stomachs were cut open along the greater curvature and gently washed with normal saline. Gastric mucosa was examined for the presence of erosions, haemorrhagic spots, ulcer and perforation, if any, with the help of a magnifying lens. The severity of the ulcers was determined by an arbitrary scoring system. ${ }^{[16]}$ The ulcer index was calculated as a mean score of ulcer severity in all the treated groups and was compared with that of control.

\section{Serum calcium}

Serum calcium was estimated in a separate group of animals. Half millilitre of blood was collected from the heart of the anaesthetized animals with the help of a $21 \mathrm{~g}$ hypodermic needle inserted into the ventricle. The serum calcium was estimated by the 0 -cresolphthalein complexone (0-сpc) method $^{[17]}$ using a kit (Accurex Biomedical private limited).

\section{Drugs and doses}

The clinical doses for various drugs were converted to ratequivalent doses with the help of a converting table devised by Paget and Barnes cited by Ghosh. ${ }^{[18]}$ Calcium carbonate (LR grade; $\mathrm{BDH}$ ) in $1 \%$ gum acacia suspension was used in 10, 25 and $50 \mathrm{mg} / \mathrm{kg}$ doses.

1. Calcium gluconate (generous gift by Korten Pharmaceuticals Pvt. Ltd., India) dissolved in water was used in $5,10,25$ and $50 \mathrm{mg} / \mathrm{kg}$ doses.

2. Aspirin (I.P. grade, Vikas, Pharma, Mumbai) in $1 \%$ gum acacia suspension was administered at 54 and $200 \mathrm{mg} / \mathrm{kg}$ doses.

3. Verapamil hydrochloride (I.P. grade, Torrent laboratories, Âhmedabad) dissolved in water was administered in the dose of $4 \mathrm{mg} / \mathrm{kg}$.

4. Magnesium sulfate (LR grade, S.D fine chemicals Ltd., Boisar) dissolved in water was used in the dose of 500 $\mathrm{mg} / \mathrm{kg}$ i.p.

In the interaction studies, aspirin, calcium carbonate and verapamil were used in their subeffective doses simultaneously, whereas magnesium sulfate was administered i.p 15 min after the oral administration of calcium carbonate.

All the procedures were performed in accordance with the guidelines issued by the Institutional Animal Ethical Committee, constituted as per the directions of the Committee for the Purpose of Control and Supervision of Experiments on Animals, Ministry of Animals Welfare Division, Government of India.

\section{Statistical analysis}

Data were expressed as mean \pm SEM and were analysed by the one-way ANOVA followed by the Dunnett's test. $P<0.05$ was considered significant.

\section{Results}

\section{Acute studies}

Carrageenan-induced paw edema in the control group did not differ from the corresponding values in the calcium carbonate $(10 \mathrm{mg} / \mathrm{kg})$-treated group, indicating the ineffective dose of calcium carbonate. On the contrary, calcium gluconate in the dose of $5 \mathrm{mg} / \mathrm{kg}$ showed a significant $(P<0.001)$ proinflammatory activity after $3 \mathrm{~h}$.

The mean paw volume at $1 \mathrm{~h}$ in the calcium carbonate (50 $\mathrm{mg}$ ) and the calcium gluconate (50 mg) groups was comparable to the corresponding value of the aspirin $(200 \mathrm{mg})$ group, indicating significant $(P<0.001)$ inhibition of oedema as compared to that of the control group. Similar antiinflammatory activity was observed in these groups at the $3^{\text {rd }}$ and $5^{\text {th }} \mathrm{h}$. [Table 1] 
Effect of various treatments in rats on carrageenan-induced paw oedema

\begin{tabular}{|c|c|c|c|c|}
\hline \multirow[t]{2}{*}{$\operatorname{Drug}(\mathrm{mg} / \mathrm{kg})$} & \multicolumn{4}{|c|}{ Paw volume in $\mathrm{ml}$} \\
\hline & $0.5 h$ & $1 \mathrm{~h}$ & $3 h$ & $5 h$ \\
\hline Control (1\% gum acacia) & $0.16 \pm 0.03$ & $0.50 \pm 0.05$ & $0.51 \pm 0.04$ & $0.65 \pm 0.10$ \\
\hline Aspirin $(200)$ & $0.05 \pm 0.03^{*}$ & $0.10 \pm 0.03^{* * *}$ & $0.06 \pm 0.04^{* * *}$ & $0.13 \pm 0.06^{* * *}$ \\
\hline Calcium carbonate (10) & $0.20 \pm 0.07$ & $0.38 \pm 0.06$ & $0.45 \pm 0.07$ & $0.40 \pm 0.08$ \\
\hline Calcium carbonate (25) & $0.20 \pm 0.02$ & $0.40 \pm 0.03$ & $0.25 \pm 0.02^{* * *}$ & $0.10 \pm 0.03^{* * *}$ \\
\hline Calcium carbonate $(50)$ & $0.01 \pm 0.02^{* * *}$ & $0.10 \pm 0.02^{* * *}$ & $0.30 \pm 0.03^{* * *}$ & $0.10 \pm 0.03^{* * *}$ \\
\hline Calcium carbonate $(10)+$ Aspirin $(54)$ & $0.03 \pm 0.02^{\star *}$ & $0.08 \pm 0.03^{* * *}$ & $0.05 \pm 0.02^{* * *}$ & $0.05 \pm 0.02^{* * *}$ \\
\hline Calcium gluconate (5) & $0.16 \pm 0.03$ & $0.31 \pm 0.09$ & $0.45 \pm 0.10^{* * *}$ & $0.48 \pm 0.09^{* * *}$ \\
\hline Calcium gluconate (10) & $0.28 \pm 0.08$ & $0.35 \pm 0.08$ & $0.16 \pm 0.07^{* * *}$ & $0.13 \pm 0.07^{\star * *}$ \\
\hline Calcium gluconate (25) & $0.15 \pm 0.03$ & $0.30 \pm 0.05^{*}$ & $0.36 \pm 0.04^{*}$ & $0.03 \pm 0.03^{* * *}$ \\
\hline Calcium gluconate $(50)$ & $0.10 \pm 0.03$ & $0.11 \pm 0.03^{* * *}$ & $0.18 \pm 0.03^{* * *}$ & $0.11 \pm 0.03^{* * *}$ \\
\hline Calcium gluconate (5) + Aspirin (54) & $0.06 \pm 0.06$ & $0.21 \pm 0.08^{* *}$ & $0.30 \pm 0.03^{* * *}$ & $00.00^{* * *}$ \\
\hline Magnesium sulfate $(500)$ & $0.62 \pm 0.12$ & $0.70 \pm 0.14$ & $1.26 \pm 0.17$ & $0.58 \pm 0.06$ \\
\hline Magnesium sulfate $(500)+$ Calcium carbonate $(50)$ & $0.31 \pm 0.08$ & $0.36 \pm 0.09$ & $0.38 \pm 0.10$ & $0.43 \pm 0.09$ \\
\hline Calcium carbonate $(10)+$ Verapamil $(4)$ & $0.17 \pm 0.04$ & $0.32 \pm 0.05^{*}$ & $0.17 \pm 0.04^{* * *}$ & $0.06 \pm 0.03^{* * *}$ \\
\hline One-way & 5.28 & 4.27 & 3.84 & 12.38 \\
\hline ANOVA & 0.01 & 0.01 & 0.01 & 0.01 \\
\hline
\end{tabular}

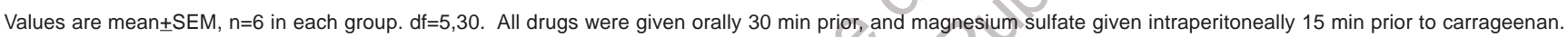
${ }^{\star} P=0.02,{ }^{* *} P=0.01,{ }^{* *} P=0.001$ when compared to control.

Table 2

Effect of various treatments in rats on granuloma dry weight, ulcer index and serum calcium

\begin{tabular}{|c|c|c|c|}
\hline Drug $(m g / k g)$ & $\begin{array}{c}\text { Granuloma - dry wt } \\
(\mathrm{mg} \% \text { of body wt) }\end{array}$ & $\begin{array}{l}\text { Ulcer } \\
\text { index }\end{array}$ & $\begin{array}{c}\text { Serum calcium } \\
\text { (mg\%) }\end{array}$ \\
\hline Control ( $1 \%$ gum acacia) & & $11.66 \pm 7.51$ & $8.68 \pm 0.23$ \\
\hline Aspirin (200) & $26.84 \pm 2.17^{\star *}$ & $40.00 \pm 0.00^{*}$ & $8.01 \pm 0.22$ \\
\hline Calcium carbonate $(50)$ & & $11.66 \pm 7.51$ & $7.98 \pm 0.23$ \\
\hline Calcium gluconate (25) & $12.95 \pm 1.81^{* *}$ & $6.66 \pm 4.96$ & $9.10 \pm 0.21$ \\
\hline Calcium carbonate $(10)+$ Aspirin (54) & $23.31 \pm 2.03^{* *}$ & $10.00 \pm 6.34$ & $9.01 \pm 0.18$ \\
\hline Calcium carbonate $(10)+$ Verapamil $(4)$ & $20.51 \pm 4.40^{* *}$ & $10.00 \pm 6.34$ & $9.05 \pm 0.13$ \\
\hline Calcium carbonate $(50)+$ Magnesium sulfate $(500)$ & $37.73 \pm 2.40$ & $3.33 \pm 2.11$ & $8.45 \pm 0.31$ \\
\hline One-way 5 & 18.24 & 4.40 & \\
\hline ANOVA & 0.01 & 0.01 & \\
\hline
\end{tabular}

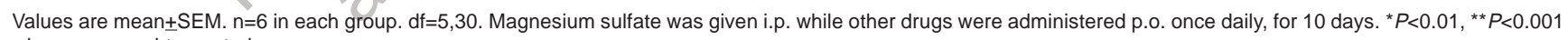
when compared to control.

The subeffective dose of calcium carbonate $(10 \mathrm{mg})$ or calcium gluconate $(5 \mathrm{mg})$ when combined with a sub-antiinflammatory dose of aspirin $(54 \mathrm{mg})$ also significantly $(P<0.01$ and $P<0.001)$ reduced paw oedema at 1 st, 3rd and 5 th $\mathrm{h}$. [Table 1] Similarly, verapamil $(4 \mathrm{mg})$ when given along with calcium carbonate $(10 \mathrm{mg})$ also significantly $(P<0.02$ and $P<0.001)$ reduced the paw oedema at 1 st, 3rd and 5th $\mathrm{h}$. However, magnesium sulfate $(500 \mathrm{mg})$ not only failed to suppress oedema but antagonized the antiinflammatory activity of calcium carbonate $(50 \mathrm{mg})$ when co-administered. Subacute studies

Mean granuloma dry weights in aspirin, calcium carbonate and calcium gluconate groups were significantly lower than the control group, indicating significant $(P<0.001)$ antiinflammatory property of aspirin and calcium salts. Similarly, co-administration of aspirin $(54 \mathrm{mg})$ or verapamil $(4 \mathrm{mg})$ with calcium carbonate $(10 \mathrm{mg})$ also showed significant $(P<0.001)$ reduction in granuloma dry weight. [Table 2] Coadministration of magnesium sulfate antagonized the effect of calcium carbonate $(50 \mathrm{mg})$, and the granuloma dry weight (37.73 \pm 2.40$)$ was comparable to the control.

In the gastric-mucosal study the mean ulcer index of the aspirin $(200 \mathrm{mg})$ group was significantly $(P<0.01)$ higher than the control group. The ulcer index in other groups was comparable to that of the control. [Table 2] None of the drug treatments caused any significant change in serum calcium. [Table 2]

A histological study of the granuloma revealed a decrease 


\section{Karnad et al.}

Figure 1. Microphotographs of granulation tissues stained with H\&E (100 X)

a. Control (vehicle)

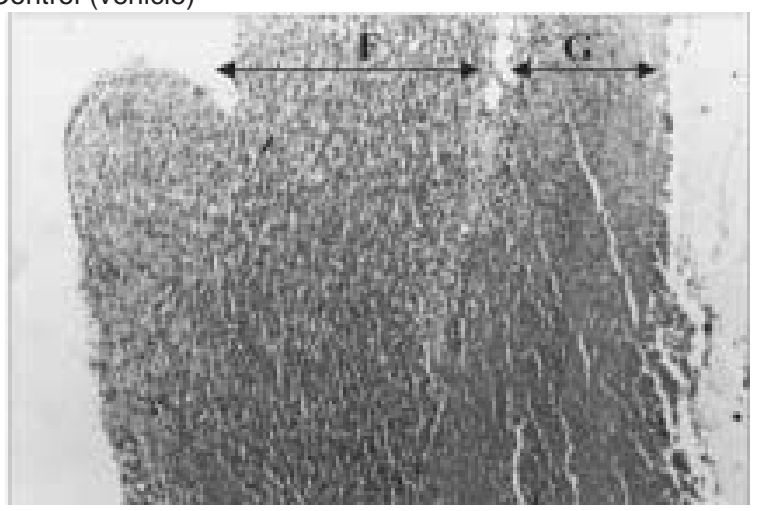

c. Calcium gluconate $(25 \mathrm{mg} / \mathrm{kg})$

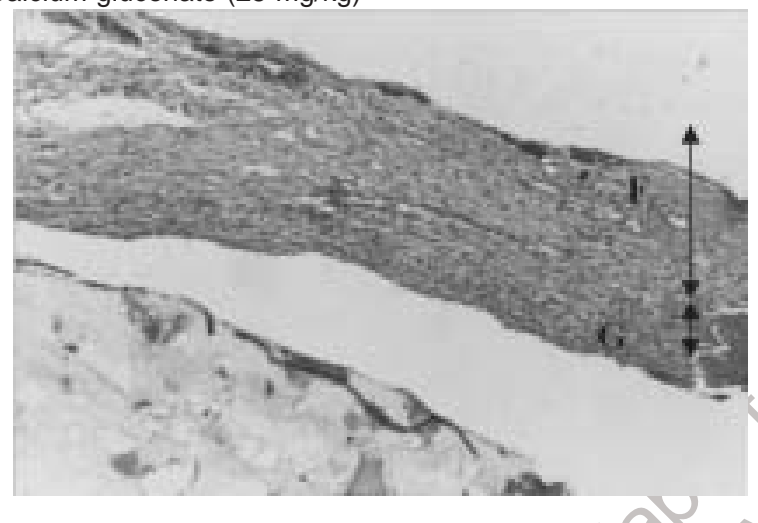

e. Calcium carbonate $(10 \mathrm{mg})$ with verapamil $(4 \mathrm{mg})$

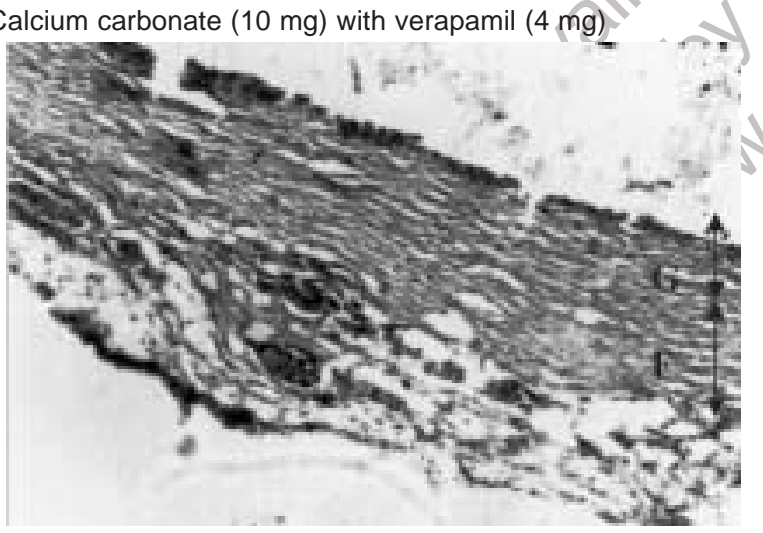

g. Calcium carbonate $(50 \mathrm{mg})$ with magnesium sulfate $(500 \mathrm{mg})$

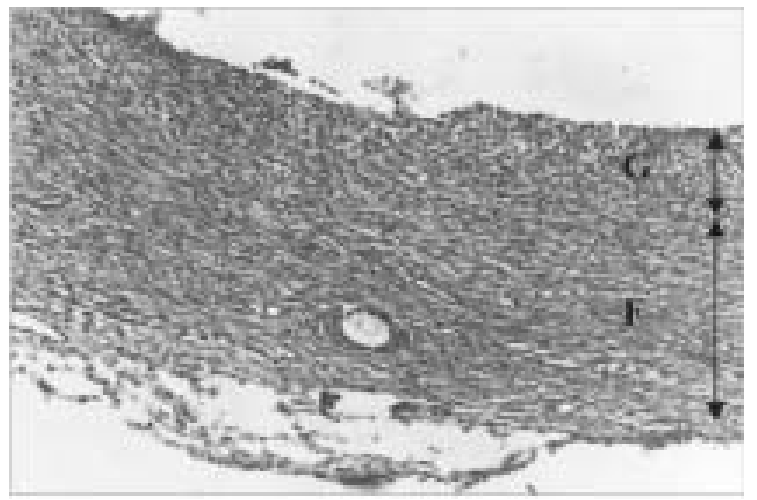

b. Aspirin $(200 \mathrm{mg} / \mathrm{kg})$

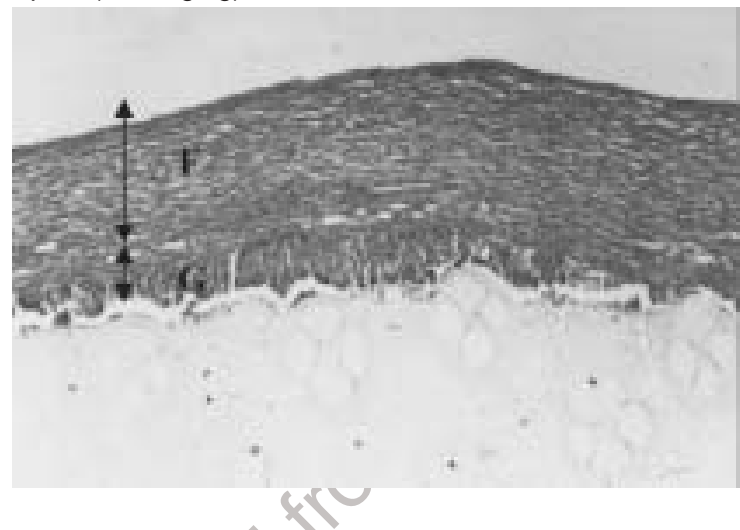

d. Calcium carbonate $(50 \mathrm{mg} / \mathrm{kg})$

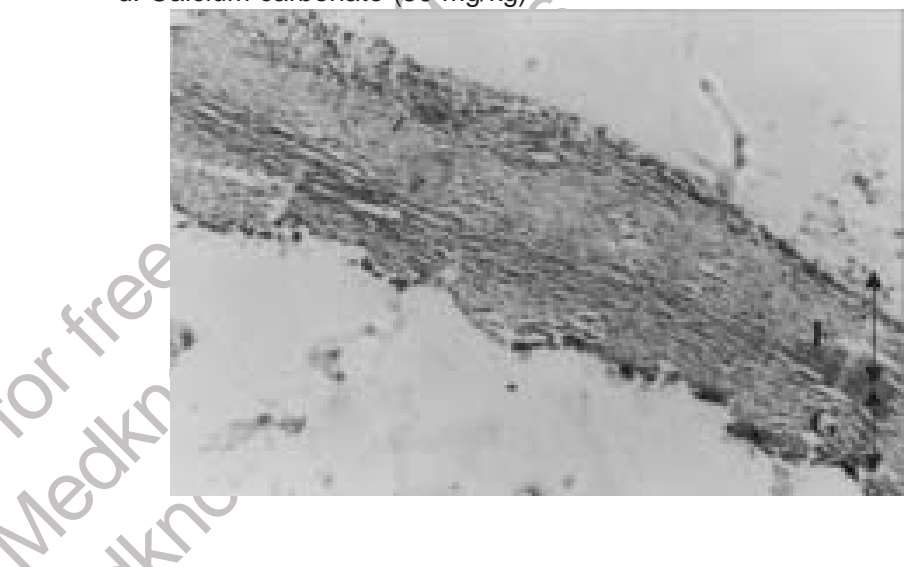

f. Calcium carbonate (10 mg) with aspirin (54 mg)

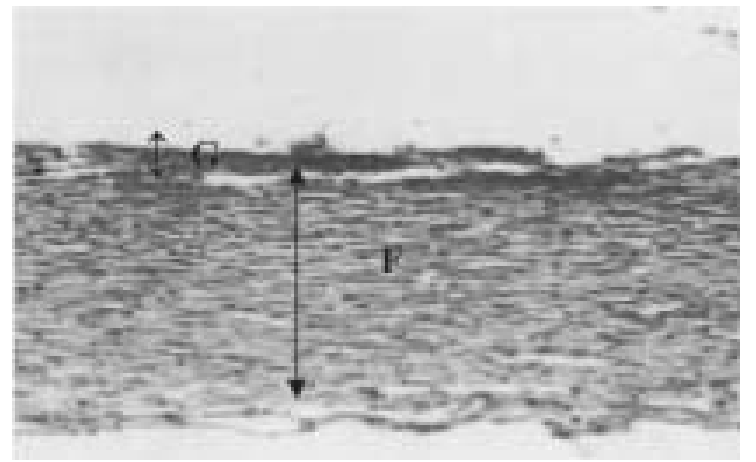

Note: Marked decrease in granulation tissue thickness $(\leftarrow \mathrm{G} \rightarrow)$ and fibroblast number $(\leftarrow \mathrm{F} \rightarrow)$ in Figure $1 \mathrm{~b}$ to $1 \mathrm{f}$ as compared to that of control (1a). $\mathrm{G}$ and $\mathrm{F}$ in Figure $1 \mathrm{~g}$ is almost comparable to that of $1 \mathrm{a}$. 
in the thickness of granulation tissue and the fibroblast number in all the treated groups (aspirin $200 \mathrm{mg}$, calcium gluconate $25 \mathrm{mg}$, calcium carbonate $50 \mathrm{mg}$ and combination of calcium carbonate $10 \mathrm{mg}$ with verapamil $4 \mathrm{mg}$ or aspirin $54 \mathrm{mg}$ ) as compared to the control, confirming their antiinflammatory property. [Figure 1] However, co-administration of magnesium sulfate with calcium carbonate failed to decrease the granulation tissue and fibroblast number.

\section{Discussion}

Results of the present study indicate that both calcium carbonate and calcium gluconate possess significant antiinflammatory property when used in clinically equivalent dose both in acute and subacute models of inflammation, which were comparable to that of aspirin. A survey of literature reveals that in different models of inflammation, calcium salts like calcium dobesilate, ${ }^{[3]}$ calcium pentosan polysulfate ${ }^{[5]}$ and

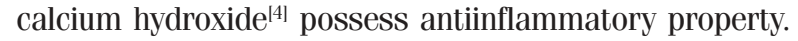

Findings of the present study corroborate the antiinflammatory property of calcium salts, and differ from some other earlier reports wherein calcium chloride ${ }^{[10]}$ failed to produce antiinflammatory activity whereas calcium gluconate ${ }^{[12]}$ enhanced inflammation. The discrepancy could be explained on the basis of the different animal models of inflammation used and the dose, the time and the route of administration of calcium salts. Klingenberg H.G., H. Dorner ${ }^{[10]}$ injected calcium salts along with the inflammogen (Sephadex) in rats, whereas Cates et al., ${ }^{[12]}$ infused calcium gluconate intravenously to produce hypercalcaemia in cats.

The sub-antiinflammatory doses of calcium carbonate (10 mg/kg) and calcium gluconate $(5 \mathrm{mg} / \mathrm{kg})$ co-administered with sub-antiinflammatory doses of aspirin $(54 \mathrm{mg} / \mathrm{kg})$ exhibited significant antiinflammatory activity in acute as well as in sub-acute models of inflammation. Such an interaction between calcium salts and aspirin appears to be poorly documented in literature. It is well known that calcium channel blockers like verapamil and cations like magnesium antagonize the pharmacological actions of calcium. However, in the present study, combined treatment of verapamil and calcium carbonate produced synergistic antiinflammatory activity in both the models, whereas magnesium sulfate antagonized the antiinflammatory activity of calcium carbonate. Again, reports regarding similar interactions are scanty in literature.

The mechanism of the antiinflammatory action of calcium cannot be proposed on the basis of the present findings, but appears to be independent of serum calcium levels since the serum calcium levels in the treated animals did not change significantly as compared to that of the control animals. However, several mechanisms have been proposed in earlier reports. Piller , has speculated that calcium dobesilate reduced the number of circulating monocytes and also blocked the action of macrophage in order to suppress inflammation. ${ }^{[3]}$ It has also been shown that calcium dobesilate can suppress platelet aggregating-factor production in endothelial cells in a dose-dependent manner. ${ }^{[19]}$ The above mechanisms may play a role in the antiinflammatory activity of calcium carbonate and calcium gluconate too.

The other proposed antiinflammatory mechanisms of calcium salts include the precipitant action of calcium on a cement substance ${ }^{[6]}$ and enhanced superoxide anions scavenging through increased activity of superoxide dismutase, peroxidase, glutathione peroxidase and glutathione reductase, which are reported to be increased by calcium glubionate. ${ }^{[20]}$ It is well known that such enzymes suppress inflammation. It is not known whether calcium salts like calcium carbonate and calcium gluconate have a property similar to that of calcium glubionate, which could explain their antiinflammatory action. Detailed studies are needed to explain the exact mechanism of action.

Calcium being an essential element for the vascular smooth muscle contraction can prevent effusion and thereby exert its antiinflammatory effect. However such a possibility appears to be quite remote since calcium salts failed to prevent effusion in earlier studies. ${ }^{[11]}$

In some smooth muscles, calcium, through the calciumsensitive potassium channels, can lead to hyperpolarization. ${ }^{[21]}$ If this is true for the vascular smooth muscle, then calcium can produce vasodilatation. In fact, calcium has been reported to produce vasodilatation by stabilizing the cell membranes. ${ }^{[22,23]}$ Due to vasodilatation the interendothelial cell gaps may be reduced, leading to decreased effusion, which is one of the events of inflammation.

The synergistic antiinflammatory activity of calcium carbonate with verapamil, as observed in the present study, indirectly indicates that calcium acts mainly extracellularly to precipitate the endothelial substance or to produce a hyperpolarization of the vascular cells and other cells releasing the inflammogens. It is well known that verapamil inhibits the release of inflammogens by restricting the calcium influx, and it has been reported to potentiate the antiinflammatory action of aspirin. ${ }^{[14]}$

With aspirin, like with verapamil, calcium interaction appears to be of a pharmacodynamic nature. The extracellular actions of calcium as mentioned above, might add to the insignificant antiinflammatory activity of a low dose of aspirin.

A higher dose of calcium carbonate $(50 \mathrm{mg} / \mathrm{kg})$ appears to produce its antiinflammatory activity mainly through its intracellular action. The antagonism of its antiinflammatory activity by magnesium sulfate could be explained on the basis of earlier study, ${ }^{[24]}$ in which magnesium sulfate has been reported to act as a calcium- channel blocker.

Studies on the gastric mucosa showed some significant ulcerogenic activity of aspirin $(200 \mathrm{mg} / \mathrm{kg})$, whereas both, the calcium salts and the combination of sub-antiinflammatory doses of aspirin and calcium carbonate, were free from ulcerogenic action despite exhibiting significant antiinflammatory activity. It is well known that calcium salts possess astringent as well as antacid properties, which may explain the lack of their ulcerogenic potential. In fact, the availability of aspirin and calcium combinations in the market, their extensive use in clinical practice and the controversial reports regarding the antiinflammatory property of calcium were the main initiatives for the present study.

The results of the present study favour the combined use of aspirin and calcium, if the present findings could be extrapolated to clinical situations. The advantages of such combined preparations are obviously a reduction in the dose 
of aspirin that could still produce significant antiinflammatory action, and a possible protection against aspirin-induced gastric toxicity. It is worthwhile to evaluate such preparations through clinical trials.

\section{Acknowledgments}

The authors are grateful to the Principal, J.N.Medical College, Belgaum, for providing facilities, and to Dr. P.R. Malur, Professor of Pathology, for his guidance in histopathology studies. Thanks to Mr. M.D. Mallapur, Biostatistician, Mr. M.D. Kankanawadi, Mr. A.V. Karwekar and Mr. M.R. Ambewadi for their valuable assistance.

\section{References}

1. Tilley BC, Alarcon GS, Heyse SP, Trentham DE, Neuner R, Kaplan DA, et al. Minocycline in rheumatoid arthritis, A 48-week, double-blind, placebo-controlled trial. MIRA Trial Group. Ann Intern Med 1995;122:81-9.

2. Spillert $\mathrm{CR}$, Spillert KR, Hollinshead MB, Lazaro EJ. Inhibitory effect of high dose ascorbic acid on inflammatory edema. Agents Actions 1989;27:401-2.

3. Piller NB. Assessment of antiinflammatory activity of calcium dobesilate. Effect on macrophages attaching to subcutaneously implanted cover slips in guinea pigs. Arznemittelforchung 1990;40:698-700.

4. Hendry JA, Jeansonne BG, Dummett Co Jr, Burrell W. Comparison of calcium hydroxide and zinc oxide and eugenol pulpectomies in primary teeth of dogs. Oral Surg - Oral Med- Oral Pathol 1982;54:445-51.

5. Smith MM, Ghosh P, Numata Y, Bansal MK. The effects of orally administered calcium pentosan polysulfate on inflammation and cartilage degeneration produced in rabbit joints by intraarticular injection of a hyaluronate- Polylysin Complex. Arthritis Rheum 1994;37:125-36.

6. Sollman TA. Manual of pharmacology and its applications to therapeutics and toxicology. Philadelphia: WB Saunders Co.; 1964. p. 1073-88.

7. Binder LS. Acute arthropod envenomation: incidence clinical features and management. Med Toxicol Adverse Drug Exp 1989;4:163-73.

8. Frolova OA, Isakova VI. The therapeutic effect of a biogenic paste in experimental chronic periodontitis. Stomatologia Mosk 1990;69:20-2.

9. Tronstad L, Wennberg A. Biologic tests of a proposed pulp capping agents (Reocap). Odontol Revy 1976;27:109-14.

10. Klingenberg HG, Dorner H. Microscopical investigations on the vessel seal- ing effect of calcium ions. Experientia 1976;32:1561-62.

11. Marcus Robert. Agents affecting calcification and bone turnover: Calcium, phosphate, parathyroid hormone, vitamin D, calcitonin and other compounds, Chapter 61 in Goodman and Gilmans. In: Hardman JG. The pharmacological Basis of therapeutics. New York: Mc Graw-Hill; 1996. p. 1519-46.

12. Cates MC, Singh SM, Peick AL, Harvey MH, Reber HA. Acute hypercalcemia, pancreatic duct permeability and pancreatitis in cats. Surgery 1988;104: 137-41.

13. Srivastava VK, Saxena KK, Gupta B. Calcium channel blockers in acute inflammation. Indian J Exp Biol 1988;26:70-1.

14. Viswanadham CK., Patil PA. Enhancement of anti-inflammatory activity of aspirin by verapamil. Indian J Med Res 1993;98:34-6.

15. Turner RA, editor. Screening Methods in Pharmacology. New York, London: Academic Press Inc.; 1965. p. 323.

16. Bhowmick S, Bose R, Pal M, Pal SP. Antiulcer activity on N-phthaloyl GABA-A new GABA mimetic agent. Indian J Exp Biol 1990;28:190-2.

17. Gitelman H. Clinical Chemistry-Calcium-O-Cresolpthalein complexone method. Anal Biochem 1967;20:521.

18. Ghosh MN. Fundamentals of Experimental Pharmacology. $3^{\text {rd }}$ ed. Kolkata: Hilton and Co.; 2005

19. Bussolino F, Biffignandi P, Arese P. Platelet activating factor- a powerful lipid autocoid possibly involved in microangiography. Acta-Haematol 1986;75: 129-40.

20. Lutnicki K, Wrobel J, Ledwozyw A, Trebas Pietras F. The effect of calcium ions on the intensity of peroxidation processes and the severity of ethanol induced injury to the rat's gastric mucosa. Arch Vet Pol 1992;32:125-32.

21. McDonald TF, Pelzer S, Trantwein W, Pelzer DJ. Regulation and modulation of calcium channels in cardiac, skeletal and smooth muscle cells. Physiol Rev 1994;74:365-507.

22. Webb RC, Bhor DF. Mechanism of membrane stabilization by calcium in vascular smooth muscle. Am J Physiol 1978;235:227-32.

23. Overbeck HW. Attenuated arteriolar dilator responses to calcium in genetically hypertensive rats. Hypertension 1984;6:647-53.

24. Breese GR, Muellar RA. Relationship of drugs acting on the central nervous system to neurotransmission. In: Paul M, Mueller R, George R, editors. Principles of Pharmacology Basic Concepts and Clinical Application. Breese, New York: Chapman \& Hall - An International Thomson Publishing Co.; 1995. p. 211-23.

\title{
PP SURYA KUMARI PRIZE
}

\section{Indian Pharmacological Society}

PP Surya Kumari prize is awarded by IPS every year for the best research paper published in any journal on "diabetes mellitus, other endocrinal and metabolic disorders" in the last five years. The prize is open to Indian scientists working in Indian laboratories. The award is presented to the winner at the annual conference of IPS.

Those who wish to compete for the prize for the year 2007 may submit five reprints/copies of the paper (published in 2002-2006) to the Chief Editor, Indian Journal of Pharmacology at the following address on or before 31st March 2007.

\author{
Prof. R. Raveendran
}

Convener, PP Surya Kumari Prize,

The Chief Editor-IJP, Department of Pharmacology,

JIPMER, Pondicherry - 605 006. India

Phone: 0413-2271969; Fax: 0413-2272067

E-mail : ijp@jipmer.edu; Website: www.ijp-online.com 